\title{
Montreal prognostic score: estimating survival of patients with non-small cell lung cancer using clinical biomarkers
}

\author{
B Gagnon *,1, J S Agulnik², I Gioulbasanis ${ }^{3}$, G Kasymjanova ${ }^{2}$, D Morris ${ }^{4}$ and N MacDonald ${ }^{5}$
}

${ }^{1}$ Department of Family Medicine and Emergency Medicine, Université Laval, Centre de Recherché du Le Centre Hospitalier Universitaire de Québec, 9 rue McMahon, Local 1899-6, Quebec, Quebec City, Quebec QC G1R 2J6, Canada; ${ }^{2}$ Division of Pulmonary Diseases, Jewish General Hospital, Lady Davis Institute for Medical Research, McGill University, 3999 Côte-SainteCatherine, Montreal, Quebec H3S 1Y7, Canada; ${ }^{3}$ Department of Oncology, University Hospital of Larissa, Biopolis, 41110, Larissa, Greece; ${ }^{4}$ Department of Medicine, Faculty of Medicine, McGill University, 3655 Promenade Sir William Osler, Montreal, Quebec H3G 1Y6, Canada and ${ }^{5}$ Department of Oncology, Faculty of Medicine, McGill University, Bronfman Cancer Center, 546 Pine Avenue West, Montreal, Quebec H2W 156, Canada

Background: For evidence-based medical practice, well-defined risk scoring systems are essential to identify patients with a poor prognosis. The objective of this study was to develop a prognostic score, the Montreal prognostic score (MPS), to improve prognostication of patients with incurable non-small cell lung cancer (NSCLC) in everyday practice.

Methods: A training cohort (TC) and a confirmatory cohort (CC) of newly diagnosed patients with NSCLC planning to receive chemotherapy were used to develop the MPS. Stage and clinically available biomarkers were entered into a Cox model and risk weights were estimated. C-statistics were used to test the accuracy.

Results: The TC consisted of 258 patients and the CC consisted of 433 patients. Montreal prognostic score classified patients into three distinct groups with median survivals of 2.5 months (95\% confidence interval (CI): 1.8, 4.2), 8.2 months (95\% Cl: 7.0, 9.4) and 18.2 months (95\% Cl: 14.0, 27.5), respectively (log-rank, $P<0.001)$. Overall, the C-statistics were 0.691 (95\% Cl: 0.685, 0.697) for the TC and 0.665 (95\% Cl: $0.661,0.670)$ for the CC.

Conclusion: The MPS, by classifying patients into three well-defined prognostic groups, provides valuable information, which physicians could use to better inform their patients about treatment options, especially the best timing to involve palliative care teams.

The majority of patients who present with advanced and incurable, non-small cell lung cancer (NSCLC) will die of their cancer within the first year after diagnosis, some quite early. Still, others may survive for more than a year. Estimation of life expectancy is therefore of paramount importance to guide the decisions taken by both patients and their physicians. Moreover, prognostic scales are necessary to establish stratification groups in clinical trials. Accurate prognostication, however, remains extremely difficult.
Studies aiming to develop prognostic indices based on readily available clinical biomarkers have been developed and applied to populations of patients with NSCLC. The modified Glasgow Prognostic Score (mGPS) is a prognostic index (PI) based on C-reactive protein (CRP) and albumin (Leung et al, 2012). The PI (Kasymjanova et al, 2010) includes CRP and white blood cell count, whereas the Royal Marsden Hospital prognostic score (Arkenau et al, 2008) specifically focuses on lactate dehydrogenase. Also, a high neutrophil-to-lymphocytes ratio has been proposed as

*Correspondence: Dr B Gagnon; E-mail: gagnon.bruno@crchuq.ulaval.ca

Received 21 March 2013; revised 6 August 2013; accepted 9 August 2013; published online 24 September 2013

(c) 2013 Cancer Research UK. All rights reserved 0007-0920/13 
a marker of poor prognosis (Yamanaka et al, 2008; Chua et al, 2011).

By integrating these various biomarkers, we aimed to develop and validate a laboratory-based prognostic score, the Montreal prognostic score (MPS), to help physicians discuss prognosis with patients with newly diagnosed advanced NSCLC planning to receive chemotherapy treatment.

\section{MATERIALS AND METHODS}

Population. This is a retrospective study using a training cohort (TC) and confirmatory cohort (CC) in order to develop a PI for survival of patients with advanced NSCLC not treated with target therapy at the time of initiation chemotherapy treatment. The TC of newly diagnosed patients with inoperable stage 3 or 4 NSCLC with an Eastern Cooperative Oncology Group performance status of $0-2$ scheduled to receive chemotherapy was composed of patients seen at the Jewish General Hospital (JGH) Pulmonary Oncology Clinic in Montreal, Quebec, Canada, between 9 April 2002 and 21 September 2008. Follow-up ended on October 2011. Dates of death were obtained from clinical charts. The majority of blood tests were taken within 3 days of the initiation of chemotherapy.

The CC of patients with the same clinical characteristics of the TC was composed of three retrospective sub-cohorts. First, a new cohort was composed of patients seen again at the JGH between 1 October 2008 and 12 April 2013, and follow-up ended on 20 June 2013. A second cohort was composed of patients seen at the University General Hospital of Heraklion Crete (UGHH), Greece between 6 February 2006 and 12 October 2010 and follow-up ended on 27 October 2011. A third cohort was composed of patients seen at the University General Hospital of Larissa (UGHL), Greece between 30 March 2010 and 13 December 2013, and follow-up ended on 1 June 2013. Dates of death for all patients were obtained from clinical charts. The study was approved by the institutional review boards of all three hospitals involved in this result project.

Statistical method. Multivariable survival analytical methods for right-censored time-to-event data were based on the following choices: time 0 was defined as the date of the first chemotherapy treatment and the event of interest was death because of any cause. We previously demonstrated that albumin and CRP violated proportional hazard $(\mathrm{PH})$ and the linearity assumptions (Gagnon et al, 2010). By choosing a 12-month follow-up period, the detrimental effects of the violation of the $\mathrm{PH}$ on the development of an optimal prognostic model were minimised. Patients who were either dead or lost to follow-up during the study period using the date of the last visit, or alive after 12 months, were censored.

Development of the MPS. To be useful in clinical practice, we dichotomised all continuous biomarkers of the TC so that a prognostic value can be easily assigned to each one. To optimally dichotomise covariates affecting survival in a non-linear way (Faraggi et al, 2001), we used the invariable survival tree growing model (Breiman et al, 1984). Second, we included in the multivariable Cox's PH model all the variables of interest: stage, CRP, albumin, lactic acid dehydrogenase (LDH) and absolute neutrophil count/lymphocyte count ratio (N/L). Third, we used the backward stepwise Cox's regression analysis for the final model with a minimum of $P=0.1$ in order to increase the prognostic value of the MPS. PHs assumptions were systematically verified for all proposed models (Grambsh and Therneau, 1994). Fourth, a prognostic score was calculated for each significant risk factor by dividing their $\beta$ estimate by the smallest one of the model and the results were rounded to the nearest 0.5 integer (Chow et al, 2008) and multiplied by 2 to produce whole numbers. Finally, the three risk group's regression-based MPS was developed by regrouping subgroups of patients with a similar median survival.

Validation of the MPS. The developed MPS based on the TC was applied on the CC. The C-statistics as in Pencina and D'Agostino (2004) were calculated for each cohort. In order to perform a fair model comparison, we used split-sample cross-validation as suggested by Harrell et al (1982). The data were split, which was set at random, into two parts: a learning sample ( 2 out of 3 ) and a validation sample (1 out of 3 ). We fit a Cox regression model for each cohort to the learning sample, and calculated the C-statistic on the validation sample. We repeated the procedure 100 times, obtaining a distribution of values of the C-statistic for each cohort from which we can calculate means, s.d. and approximate $95 \%$ confidence intervals (CIs). Twelve regression models were fitted for each cohort: one for each month of our observation time where patients who died after that month were considered censored. We presented the results graphically to facilitate the interpretation.

Descriptive analyses and conventional Cox's PH regression were performed using the statistical software package 'R' (R Foundation for Statistical Computing, Vienna, Austria) with version 2.12.0 (Therneau and Atkinson, 1997). The models based on the survival tree growing were fit using the 'Rpart' software library developed by Therneau and Atkinson (1997).

\section{RESULTS}

Population. During the study period of the TC, out of the eligible 408 patients seen, 258 (63.2\%) patients were included in the study. The other patients had missing data, mostly CRP as it was routinely tested only after January 2005. For the CC, there were 235 eligible patients seen at the JGH during the study period and $223(85.4 \%)$ patients were included in the study (CRP and other co-variates were not available for 12 patients), and 4 were lost to follow-up. There were 249 eligible patients seen at the UGHH and UGHL, of whom 210 $(83.3 \%)$ patients were included (CRP and other co-variates were missing in 39 patients). Therefore, the CC included 433 patients. A total of $36(11.1 \%)$ patients in the CC were lost to follow-up.

Table 1 presents the characteristics of the patients for each cohort. Compared with the TC, the CC had a higher percentage of patients who were male, had stage 4 cancer, an albumin concentration $>38 \mathrm{gl}^{-1}$ and a CRP concentration $\leqslant 10 \mathrm{mgl}^{-1}$.

PI based on the TC. Table 2 presents the univariate and multivariate $\beta$ estimates of Cox's model for each biomarker and the corresponding prognostic value of significant ones. Age, sex, smoking status, percent weight loss in the preceding 6 months and albumin did not retain independent prognostic value. With stage ( $\beta$ : $0.479 ; 95 \%$ CI: $0.074,0.883)$, the following independent biomarkers were included in the model: CRP $(\beta$ : $0.581 ; 95 \% \mathrm{CI}$ : $0.225,0.936)$, LDH $(\beta: 0.413 ; 95 \%$ CI: $0.068,0.758)$ and $N / L$ ( $\beta: 0.607 ; 95 \%$ CI: $0.268,0.945)$. Albumin, having the smallest $\beta$ estimate, served as denominator to calculate the relative prognostic values of the other covariates. Therefore, a patient may have a total prognostic score varying from 0 to 13 depending on the total prognostic value for all their prognostic factors.

Table 3 shows how patients were classified according to their median survivals based on their total prognostic scores. The MPS classified patients into three groups: 21 patients with weeks of life (total prognostic score: 18), 152 with months of life (total prognostic score: $4-12$ ) and 85 with more than a year of life (total prognostic score: $0-3$ ). The total prognostic scores translate respectively into median survival in months of 2.5 (95\% CI: 1.8, 4.2), 8.2 (95\% CI: 7.0, 9.4) and 18.2 (95\% CI: 14.0, 27.5), (log-rank, $P<0.001)$. Of note, CIs were not overlapping for any of the risk groups. For the TC, there was no relationship between chemotherapy regimen and MPS risk group $(P=0.118)$. 
Table 1. Patient characteristics

\begin{tabular}{|c|c|c|c|c|}
\hline & & $\begin{array}{l}\text { Training cohort } \\
\qquad(\mathbf{N}=\mathbf{2 5 8 )}\end{array}$ & $\begin{array}{l}\text { Confirmatory cohort } \\
\qquad(N=433)\end{array}$ & $\boldsymbol{P}$-value \\
\hline Variable & Cut point & \# (\%) & \# (\%) & \\
\hline Age & $\begin{array}{l}<65 \text { years } \\
\geqslant 65 \text { years }\end{array}$ & $\begin{array}{l}123(47.7) \\
135(52.3)\end{array}$ & $\begin{array}{l}199(46.0) \\
234(54.0)\end{array}$ & 0.662 \\
\hline Sex & $\begin{array}{l}\text { Female } \\
\text { Male }\end{array}$ & $\begin{array}{l}129(50.0) \\
129(50.0)\end{array}$ & $\begin{array}{l}140(32.3) \\
293(67.7)\end{array}$ & $<0.001$ \\
\hline Stage & $\begin{array}{l}\text { III } \\
\text { IV }\end{array}$ & $\begin{array}{r}69(26.7) \\
189(73.3)\end{array}$ & $\begin{array}{r}65(15.0) \\
368(85.0)\end{array}$ & $<0.001$ \\
\hline Performance status (ECOG) & $\begin{array}{l}0-1 \\
2\end{array}$ & $\begin{array}{r}213(82.6) \\
45(17.4)\end{array}$ & $\begin{array}{r}343(79.2) \\
90(20.8)\end{array}$ & 0.284 \\
\hline Smoking status & $\begin{array}{l}\text { Never } \\
\text { Ever }\end{array}$ & $\begin{array}{r}39(15.1) \\
219(84.9)\end{array}$ & $\begin{array}{r}65^{\mathrm{a}}(15.1) \\
366^{\mathrm{a}}(84.9)\end{array}$ & 0.990 \\
\hline Weight loss in the preceding 6 months & $\begin{array}{l}<5 \% \\
\geqslant 5 \%\end{array}$ & $\begin{array}{r}162(62.8) \\
96(37.2)\end{array}$ & $\begin{array}{l}175^{\mathrm{b}}(51.3) \\
166^{\mathrm{b}}(48.7)\end{array}$ & 0.005 \\
\hline Chemotherapy $^{c}$ & $\begin{array}{l}\text { Double } \\
\text { Single }\end{array}$ & $\begin{array}{r}197(76.4) \\
61(23.6)\end{array}$ & $\begin{array}{l}293^{\mathrm{d}}(68.3) \\
136^{\mathrm{d}}(31.7)\end{array}$ & 0.024 \\
\hline Pathology (NSCLC) & $\begin{array}{l}\text { Adenocarcinoma } \\
\text { Other }\end{array}$ & $\begin{array}{r}166(64.3) \\
92(35.7)\end{array}$ & $\begin{array}{l}300(69.3) \\
133(30.7)\end{array}$ & 0.180 \\
\hline C-reactive protein & $\begin{array}{l}\leqslant 10 \mathrm{mgl}^{-1} \\
>10 \mathrm{mgl}^{-1}\end{array}$ & $\begin{array}{l}107(41.5) \\
151(58.5)\end{array}$ & $\begin{array}{l}264(61.0) \\
169(39.0)\end{array}$ & $<0.001$ \\
\hline Albumin & $\begin{array}{l}>38 \mathrm{gl}^{-1} \\
\leqslant 38 \mathrm{gl}^{-1}\end{array}$ & $\begin{array}{r}178(69.0) \\
80(31.0)\end{array}$ & $\begin{array}{l}245(56.6) \\
188(43.4)\end{array}$ & 0.001 \\
\hline Lactate dehydrogenase & $\begin{array}{l}\leqslant 250 \mathrm{UI}^{-1} \\
>250 \mathrm{Ul}^{-1}\end{array}$ & $\begin{array}{r}183(70.9) \\
75(29.1)\end{array}$ & $\begin{array}{l}282(65.1) \\
151(34.9)\end{array}$ & 0.116 \\
\hline Absolute neutrophil count/lymphocytes & $\begin{array}{l}\leqslant 4.5 \\
>4.5 \\
\end{array}$ & $\begin{array}{l}150(58.1) \\
108(41.9) \\
\end{array}$ & $\begin{array}{l}219(50.6) \\
214(49.4) \\
\end{array}$ & 0.054 \\
\hline \multicolumn{5}{|c|}{$\begin{array}{l}\text { Abbreviations: ECOG = Eastern Cooperative Oncology Group; NSCLC = non-small cell lung cancer. } \\
a_{N=431} \\
\mathbf{b}_{N=341} \\
c_{A} \text { All include platinum-based chemotherapy. } \\
{ }^{d} N=429 .\end{array}$} \\
\hline
\end{tabular}

Table 2. Results of the univariate and backward stepwise multivariate Cox's proportional hazard model and the prognostic values for each prognostic factor for the training cohort $(N=258)$

Univariate model

Backward stepwise multivariate model

\begin{tabular}{|c|c|c|c|c|c|}
\hline Variable & $\beta$ Estimates $(95 \% \mathrm{Cl})$ & $\boldsymbol{P}$-value & $\beta$ Estimates $(95 \% \mathrm{Cl})$ & $P$-value & Prognostic values \\
\hline Age ( $\geqslant 65$ vs $<65$ years $)$ & $0.108(-0.210,0.426)$ & 0.505 & - & - & - \\
\hline Sex (male vs female) & $0.341(0.021,0.660)$ & 0.037 & - & - & - \\
\hline Stage (IV vs III) & $0.662(0.263,1.062)$ & 0.001 & $0.479(0.074,0.883)$ & 0.021 & 3 \\
\hline Performance status (ECOG) (2 vs 0-1) ${ }^{\mathrm{a}}$ & $0.801(0.421,1.180)$ & $<0.001$ & - & - & - \\
\hline Smoking status (ever vs never) & $0.629(0.111,1.147)$ & 0.017 & - & - & - \\
\hline Weight loss in the preceding 6 months ( $\geqslant 5 \%$ vs $<5 \%$ ) & $0.238(-0.086,0.562)$ & 0.150 & - & - & - \\
\hline C-reactive protein $\left(>10 \mathrm{vs} \leqslant 10 \mathrm{mgl}^{-1}\right)$ & $0.765(0.422,1.107)$ & $<0.001$ & $0.581(0.225,0.936)$ & 0.001 & 3 \\
\hline Albumin $\left(\leqslant 38 v s>38 \mathrm{gl}^{-1}\right)$ & $0.856(0.530,1.182)$ & $<0.001$ & $0.374(0.020,0.728)$ & 0.039 & 2 \\
\hline Lactate dehydrogenase ( $>250 v s \leqslant 250 \mathrm{UI}^{-1}$ ) & $0.720(0.390,1.051)$ & $<0.001$ & $0.413(0.068,0.758)$ & 0.019 & 2 \\
\hline Absolute neutrophil count/lymphocytes ( $>4.5$ vs $\leqslant 4.5$ ) & $0.859(0.540,1.178)$ & $<0.001$ & $0.607(0.268,0.945)$ & $<0.001$ & 3 \\
\hline
\end{tabular}

Results of the validation of the MPS. The application of the MPS classified the patients of the CC into the defined survival groups with corresponding median survivals in months that are quite similar to the TC: 3.3 (95\% CI: 1.6, 5.7), 7.5 (95\% CI: 6.7, 8.9) and 22.3 (95\% CI: 18.3, 31.4), respectively, (log-rank, $P<0.001$ ). Overall, the TC had a C-statistic of $0.691(95 \%$ CI: 0.685 , 


\begin{tabular}{|c|c|c|c|c|c|}
\hline \multirow[b]{2}{*}{ Groups } & \multirow[b]{2}{*}{$\begin{array}{l}\text { Total prognostic scores based } \\
\text { on five prognostic values }\end{array}$} & \multicolumn{2}{|c|}{ Training cohort $(\mathbf{N}=258)$} & \multicolumn{2}{|c|}{ Confirmatory cohort $(N=433)$} \\
\hline & & $\begin{array}{l}\text { Number of } \\
\text { patients }\end{array}$ & $\begin{array}{l}\text { Median survival time (in months) } \\
\qquad(95 \% \mathrm{Cl})\end{array}$ & $\begin{array}{l}\text { Number of } \\
\text { patients }\end{array}$ & $\begin{array}{l}\text { Median survival time (in months) } \\
\qquad(95 \% \mathrm{Cl})\end{array}$ \\
\hline 1 & $0-3$ & 85 & $18.2(14.0,27.5)$ & 101 & $22.3(18.3,31.4)$ \\
\hline 2 & $4-12$ & 152 & $8.2(7.0,9.4)$ & 306 & $7.5(6.7,8.9)$ \\
\hline 3 & 13 & 21 & $2.5(1.8,4.2)$ & 26 & $3.3(1.6,5.7)$ \\
\hline
\end{tabular}

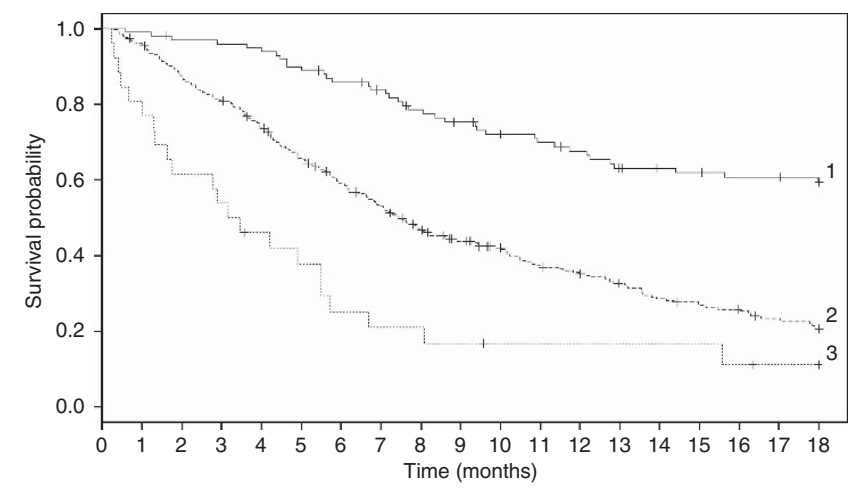

Figure 1. Kaplan-Meier curves over 18 months for the CC. MPS groups: $1,2,3$.

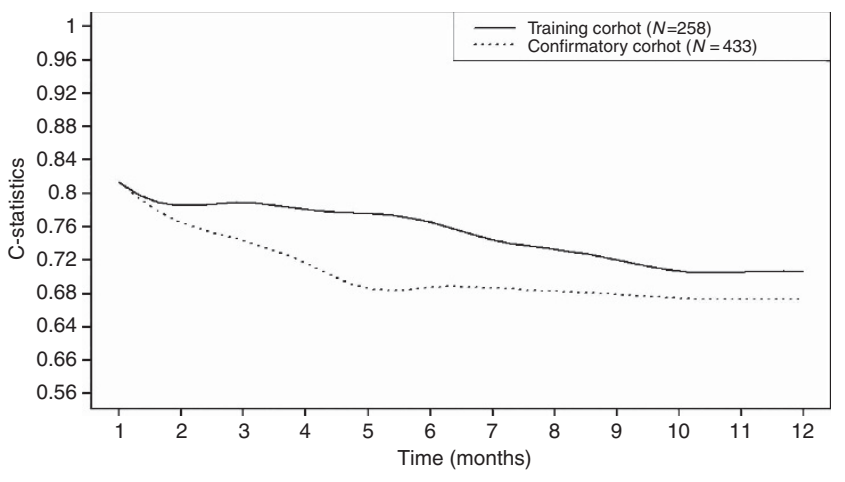

Figure 2. Results of the changes of the C-statistics over time based on Cox's PH model for the MPS based on the TC and CC.

0.697) whereas the CC had a C-statistic of 0.665 (95\% CI: 0.661 , 0.670 ). Figure 1 shows the Kaplan-Meier curves over 18 months for the CC using the MPS.

Figure 2 presents the evolution over time of the C-statistics for the TC and the CC. For example, the graph shows that the C-statistics value of the MPS for the TC was around $0.82,0.79$ and 0.78 at 1 month, 3 months and 6 months, respectively.

\section{DISCUSSION}

In this retrospective study with two different cohorts of patients, we have demonstrated that inexpensive and easily available routine haematological and biochemical investigations in combination with baseline performance status allow the construction of a highly effective PI.

In our study, in addition to stage, neutrophil-to-lymphocyte ratio, $\mathrm{CRP}$ and $\mathrm{LDH}$ were found to be important prognostic biomarkers. C-reactive protein is a commonly used and inexpensive indicator of an inflammatory state (McMillan, 2009). In a series of studies, McMillan and his associates have demonstrated that the presence of a high CRP connotes a grim prognosis for both early stage patients with resectable cancers and those with advanced cancer, across a broad spectrum of tumour types (McMillan, 2009). Although CRP production by the liver is closely linked to interleukin 6 production, its elevated presence reflects a more general systematic inflammatory state (Liu et al, 2010). The mGPS, which includes CRP, was recently shown to predict toxicity and tumour response in patients with lung cancer treated with CDDP-based chemotherapy (Gioulbasanis et al, 2012).

Neutrophil levels have long been used to alert clinicians to the presence of an inflammatory state. High ratios of neutrophil-tolymphocyte counts have been shown to be associated with poor cancer outcomes (Proctor et al, 2011; Guthrie et al, 2013). Our results confirm that a neutrophil-to-lymphocyte ratio keeps a strong prognostic value independent of other biomarkers.

The inclusion of the biomarkers in the MPS seems primarily, but not exclusively, to relate to the presence of a chronic inflammatory state with production of tumour-promoting factors by both the tumour and an aberrant immune system response. Albumin, one of the two biomarkers of the mGPS, also maintained independent prognostic value in the MPS. As in Al-Shaiba et al (2004), albumin in our study had a moderate correlation with CRP suggesting that both are markers of inflammation. Severe hypoalbuminaemia denotes a patient population with a very poor prognosis (Nixon et al, 1980). This was confirmed by Gagnon et al (2010) using a flexible modelling of survival analysis, who showed that albumin had lost its prognostic value after 6 months of follow-up.

In 1924, Warburg described that cancer cells, even in the presence of ample oxygen supply, uptake a larger amount of glucose and produce more lactate than normal cells (Warburg, 1956). To produce energy they switch from using oxidative phosphorylation to aerobic-anaerobic glycolysis. Key to this metabolic shift is the activation of hypoxia-inducing factor-1, a transcription factor targeting hundreds of genes including same controlling metabolism and inflammation (Semenza, 2011). Notable among these genes are those which lead to the production of the enzyme $\mathrm{LDH} 5$, which results in the conversion of pyruvate to lactate (Semenza, 2011). Conversion to glycolytic metabolism is a wasteful energy process but it could have advantages for the cancer cell, protecting it from oxidative stress and selectively sustaining many tumour cell functions (Warburg, 1956). Koukourakis et al (2003) found in a cohort of 112 patients with NSCLC that LDH 5 was a predictor of poor survival. Induction of LDH 5 activity within cancer cells is moderately correlated to serum LDH level (Koukourakis et al, 2005), although to some extent other pathophysiological processes such as cell death may contribute to raised levels.

Unquestionably, the markers used in the MPS are associated with a poor aggregate cancer prognosis as demonstrated in 
multiple publications studying them individually or combined. It is a tool offering prognostic information on patient subsets with markedly different patterns of survival. Therefore, the MPS adds an important component to the canon that clinicians use to guide patients and their families.

Notwithstanding the marked survival differences in those with or without inflammatory-metabolic markers, this information, seemingly, has not reached trial investigators; their patients are seldom, if ever, stratified using these markers. To date, the authors have not encountered any NSCLC clinical trials stratified by patient inflammatory status. The compelling body of evidence of McMillan et al, strongly supported by other investigators, clearly shows that the presence of a chronic inflammatory state has a strong influence on tumour progress.

Prospective clinical trials using them may prove the existence of subsets that have varied responses to chemotherapy, both in initial anatomic response and in long-term value of a response for a patient. The identification of a population where standard chemotherapy is futile has profound benefits for patients, clinicians and the health-care system. Patients can make more informed decisions, which may include abjuring chemotherapy in favour of other options including clinical trial participation aimed at relief of suffering, or palliative care options which, in their own right, will improve quality of life (Temel et al, 2010).

Cancer care in the future will be personalised care, with decisions increasingly based on aberrant genetic profiles. Some genetic profiles may also relate to the genesis of a chronic inflammatory state. To date, genetic marker research and studies on inflammation are not linked. We suggest that further refinement of prognostic accuracy may emerge if EGFR studies, as one example are reported in conjunction with the Glasgow scale or the Montreal prognostic scale.

Recently, an ASCO expert panel recommended 'that combined standard oncology care and palliative care should be considered early in the course of illness for any patient with metastatic cancer and/or high symptom burden' (Smith et al, 2012). All patients with an incurable cancer should have access to palliative care. Currently, available resources and acceptance by the broad oncologic community may impede reaching this goal. Our study identifies patient subsets who, at diagnosis have survival measured in only a few weeks or months. Surely these patients and their families should be able to and encouraged to work with palliative care teams, regardless of their symptoms burden as too often referrals are unduly delayed (Osta et al, 2008). For patients with an estimated year plus to live, it may be more practical to involve a palliative care team at diagnosis only to patients with specific needs necessitating specialised palliative care teams. However, the palliative care team should be involved if these patients present with high symptom burden or show signs of rapid deterioration. Along the disease trajectory, the monitoring of patients should be carried out to identify patients in need of palliative care.

Our study has some limitations. The retrospective nature of the constitution of our cohorts from different cancer centres may have induced a bias, especially as clinical characteristics and biomarkers were not available for all of them. In addition, the laboratory methods used to measure the blood levels of our biomarkers were not standardised across centres, although it is unlikely that this would have a major effect on the validity of the MPS. Although the CC differed from the TC in a number of clinical characteristics, the MPS performed similarly in both cohorts.

\section{CONCLUSION}

Using two distinct retrospective cohorts of patients with advanced NSCLC exposed to systemic therapy, we were able to develop and validate a new prognostic score on survival. We suggest that the MPS is a tool enriching the advice clinicians can offer their patients. Prognostic formulas using commonly obtained data should be included in clinical trials.

\section{ACKNOWLEDGEMENTS}

We thank Victor Cohen, MD, Jewish General Hospital, Lady Davis Institute for Medical Research, McGill University; Carmela Pepe, MD, Jewish General Hospital, Lady Davis Institute for Medical Research, McGill University; David I Small, MD, Jewish General Hospital, Lady Davis Institute for Medical Research, McGill University; Lin Yang, MSc, Division of Clinical Epidemiology, McGill University Health Centre, Montreal. Eleni Isidora Perdikouri University Hospital, Larissa, Greece; V Georgoulias, MD, University Hospital of Heraklion, Crete, Greece; Eleni-Isidora Perdikouri, MD, Registrar of Medical Oncology, University Hospital of Larissa, Crete, Greece; Michalitsa Makridou, Chemotherapy Department, University Hospital of Larissa, Crete, Greece; Christos N Papandreou, MD, Medical Oncology, University Hospital of Larissa, Thessaly, Greece for their support in this study. The project was partially funded by the Terry Fox Research Institute, the Canadian Institute for Health Research and the Mona Zavalkoff Fund for Pulmonary Oncology. B Gagnon is recipient of 'Chercheur-clinicien Boursier' award from the Fonds de la Recherche Québec Santé.

\section{CONFLICT OF INTEREST}

The authors declare no conflict of interest.

\section{REFERENCES}

Al-Shaiba R, McMillan DC, Angerson WJ, Leen E, McArdle CS, Horgan P (2004) The relationship between hypoalbuminaemia, tumour volume and the systemic inflammatory response in patients with colorectal liver metastases. Br J Cancer 91(2): 205-207.

Arkenau HT, Olmos D, Ang JE, de BJ, Judson I, Kaye S (2008) Clinical outcome and prognostic factors for patients treated within the context of a phase I study: the Royal Marsden Hospital experience. Br J Cancer 98(6): 1029-1033.

Breiman L, Friedman J, Olshen R, Stone C (1984) Classification and Regression Trees. Wadsworth International Group: Belmont, CA.

Chow E, Abdolell M, Panzarella T, Harris KE, Bezjak A, Warde P, Tannock I (2008) Predictive model for survival in patients with advanced cancer. J Clin Oncol 26(36): 5863-5869.

Chua W, Charles KA, Baracos VE, Clarke SJ (2011) Neutrophil/lymphocyte ratio predicts chemotherapy outcomes in patients with advanced colorectal cancer. Br J Cancer 104(8): 1288-1295.

Faraggi D, LeBlanc M, Crowley JJ (2001) Understanding neural networks using regression trees: an application to multiple myeloma survival data. Stat Med 20(19): 2965-2976.

Gagnon B, Abrahamowicz M, Xiao Y, Beauchamp ME, MacDonald N, Kasymjanova G, Kreisman H, Small D (2010) Flexible modeling improves assessment of prognostic value of C-reactive protein in advanced non-small cell lung cancer. Br J Cancer 102(7): 1113-1122.

Gioulbasanis I, Pallis A, Vlachostergios PJ, Xyrafas A, Giannousi Z, Perdikouri IE, Makridou M, Kakalou D, Georgoulias V (2012) The Glasgow Prognostic Score (GPS) predicts toxicity and efficacy in platinum-based treated patients with metastatic lung cancer. Lung Cancer 77(2): 383-388.

Grambsh PM, Therneau TM (1994) Proportional hazards tests and diagnostics based on weighted residuals. Biometrika 81: 515-526.

Guthrie GJK, Roxburgh CSD, Farhan-Alanie OM, Horgan PG, McMillan DC (2013) Comparison of the prognostic value of longitudinal measurements of systemic inflammation in patients undergoing curative resection of colorectal cancer. Br J Cancer 109(1): 24-28. 
Harrell Jr FE, Califf RM, Pryor DB, Lee KL, Rosati RA (1982) Evaluating the yield of medical tests. JAMA 247(18): 2543-2546.

Harrell Jr FE, Lee KL, Mark DB (1996) Multivariable prognostic models: issues in developing models, evaluating assumptions and adequacy, and measuring and reducing errors. Stat Med 15(4): 361-387.

Kasymjanova G, MacDonald N, Agulnik JS, Cohen V, Pepe C, Kreisman H, Sharma R, Small D (2010) The predictive value of pre-treatment inflammatory markers in advanced non-small-cell lung cancer. Curr Oncol 17(4): 52-58.

Koukourakis MI, Giatromanolaki A, Simopoulos C, Polychronidis A, Sivridis E (2005) Lactate dehydrogenase 5 (LDH5) relates to up-regulated hypoxia inducible factor pathway and metastasis in colorectal cancer. Clin Exp Metastasis 22(1): 25-30.

Koukourakis MI, Giatromanolaki A, Sivridis E, Bougioukas G, Didilis V, Gatter KC, Harris AL (2003) Lactate dehydrogenase-5 (LDH-5) overexpression in non-small-cell lung cancer tissues is linked to tumour hypoxia, angiogenic factor production and poor prognosis. Br J Cancer 89(5): 877-885.

Leung EY, Scott HR, McMillan DC (2012) Clinical utility of the pretreatment glasgow prognostic score in patients with advanced inoperable non-small cell lung cancer. J Thorac Oncol 7(4): 655-662.

Liu Y, Fuchs J, Li C, Lin J (2010) IL-6, a risk factor for hepatocellular carcinoma: FLLL32 inhibits IL-6-induced STAT3 phosphorylation in human hepatocellular cancer cells. Cell Cycle 9(17): 3423-3427.

McMillan DC (2009) Systemic inflammation, nutritional status and survival in patients with cancer. Curr Opin Clin Nutr Metab Care 12(3): 223-226.

Nixon DW, Heymsfield SB, Cohen AE, Kutner MH, Ansley J, Lawson DH, Rudman D (1980) Protein-calorie undernutrition in hospitalized cancer patients. Am J Med 68(5): 683-690.

Osta BE, Palmer JL, Paraskevopoulos T, Pei BL, Roberts LE, Poulter VA, Chacko R, Bruera E (2008) Interval between first palliative care consult and death in patients diagnosed with advanced cancer at a comprehensive cancer center. J Palliative Med 11(1): 51-57.
Pencina MJ, D'Agostino RB (2004) Overall C as a measure of discrimination in survival analysis: model specific population value and confidence interval estimation. Stat Med 23(13): 2109-2123.

Proctor MJ, Morrison DS, Talwar D, Balmer SM, Fletcher CD, O’Reilly DS, Foulis AK, Horgan PG, McMillan DC (2011) A comparison of inflammation-based prognostic scores in patients with cancer. A Glasgow Inflammation Outcome Study. Eur J Cancer 47(17): 2633-2641.

Semenza GL (2011) Oxygen sensing, homeostasis, and disease. N Engl J Med 365(6): 537-547.

Smith TJ, Temin S, Alesi ER, Abernethy AP, Balboni TA, Basch EM, Ferrell BR, Loscalzo M, Meier DE, Paice JA, Peppercorn JM, Somerfield M, Stovall E, Von Roenn JH (2012) American Society of Clinical Oncology provisional clinical opinion: the integration of palliative care into standard oncology care. J Clin Oncol 30(8): 880-887.

Temel JS, Greer JA, Muzikansky A, Gallagher ER, Admane S, Jackson VA, Dahlin CM, Blinderman CD, Jacobsen J, Pirl WF, Billings JA, Lynch TJ (2010) Early palliative care for patients with metastatic non-small-cell lung cancer. N Engl J Med 363(8): 733-742.

Therneau TM, Atkinson EJ (1997) An introduction to recursive partitioning using the rpart routines 61, Mayo Clinic, Rochester, Department of Health Science Research.

Warburg O (1956) On the origin of cancer cells. Science 123(3191): 309-314. Yamanaka T, Matsumoto S, Teramukai S, Ishiwata R, Nagai Y, Fukushima M (2008) The baseline ratio of neutrophils to lymphocytes is associated with patient prognosis in advanced gastric cancer. Oncology 73(3-4): 215-220.

This work is published under the standard license to publish agreement. After 12 months the work will become freely available and the license terms will switch to a Creative Commons AttributionNonCommercial-Share Alike 3.0 Unported License. 